\title{
2. ニューラルネットワークの利用技術
}

株式会社東芝 新 井 政 彦

\section{1. はじめに}

最近の計算機の発達は目覚ましく, 手軽に適 用できなかった技術が容易に使えるようになっ て来た。ニューラルネットワークもその一つで, 論理処理やファジィ処理などを含めたいわゆる 知識処理技術が，さまざまに応用されている。 しかしながら，ニューラルネットワーク利用技 術は, 他の方法と比べかなり異なった特徴を 持っている。即ち, 他の方法が知識処理アルゴ リズムを計算機上で実現しょうとするのに対し， ニューラルネットワークは, それが機能してい ると思われるハード（神経回路網）そのものを 何らかの形で模擬しょうとするからである。当 然, 人間の脳細胞を持って来て神経回路網を研 究または利用する事は重要であるが, 多くの利 用は計算機上あるいは何らかのデバイスで模擬 して行われる。この意味でアーティフィシャル ニューラルネットワークと呼ばれる場合も多い。 研究の視点として, 知識処理技術以外に, 特殊 な “回路”とする見方もあり，一見人間の知的 活動とは関係無いと思われる分野への適用も考 えられている。

以下で, ニューラルネットワークのモデル例, それらの性質を述べ, 適用分野の紹介を行い ニューラルネットワークの利用技術について考 えてみたい。

\section{2. 神経細胞のモデル化}

ニューラルネットワークのモデル化を行う際 に基本的な事は, 一つ一つの神経細胞（二ュー ロン）のモデル化である。有名なものとしては， 1943年, McCullochーPitts ${ }^{1)}$ により提案された ものがある。図 1 にモデル化されたニューロン

システム・ソフトウェア技術研究所

川崎市幸区柳町70

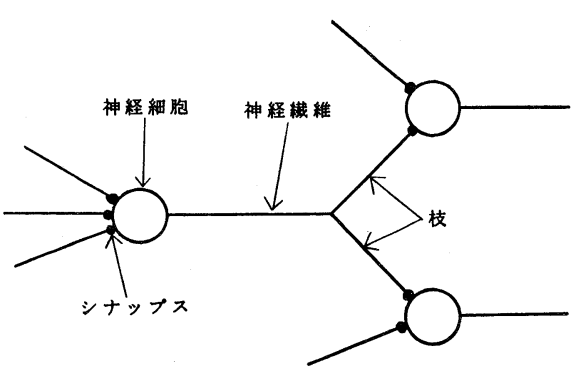

図 1 、神経回路網のモデル

間の結合関係を示すが，基本的には，シナップ スを通して何らかの信号を他のニューロンから 受け取り、シナップスを通して信号を他の ニューロンに送るものであると言って良い。こ の時, シナップスの性能の違いを現わすものと して結合の重み $\mathrm{W}_{\mathrm{ij}}$ を考える。ここで $\mathrm{i}, \mathrm{j}$ はそ れぞれ $\mathrm{i}$ 番目のニューロン, $\mathrm{j}$ 番目のニューロ

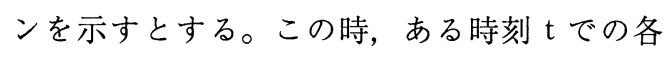
ニューロンの状態を定義して $\mathrm{U}_{\mathrm{i}}(\mathrm{t})$ とすると 時刻 $t+1$ での状態が

$$
\mathrm{U}_{\mathrm{i}}(\mathrm{t}+1)=\mathrm{f}\left(\sum_{\mathrm{j}} \mathrm{W}_{\mathrm{ij}} \mathrm{U}_{\mathrm{j}}(\mathrm{t})-\tau_{\mathrm{i}}\right)
$$

で定められると言うものである。ここで $\tau_{\mathrm{i}}$ は, しきい值であり，関数 $\mathrm{f}$ の形は，図 2 に示すよ うな（ 0,1$)$ または $(-1,1)$ の間の值を

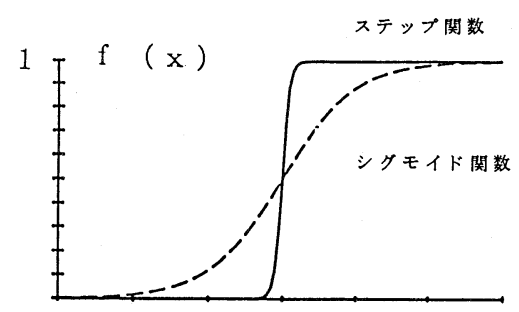

0

図 2 ニューロンの特性関数

\section{$\mathrm{x}$}


とる単調増加関数である。 $\mathrm{W}_{\mathrm{ij}}$ の符号は正負あ り，正の場合は，ニューロンを活性化させる意 味で興奮性の結合, 負の時は, 逆に活性化を弱 めるので抑制性の結合と呼ばれ，実際に，シ ナップスの結合もこれらに対応した二つの種類 があることが知られている。

ニューラルネットワークは, これらのニュー ロンが結合したものであり，関数 $\mathrm{f}$ が決まって いれば,ネットワークの特性は, 重み $\mathrm{W}_{\mathrm{ij}}$ と $\tau_{\mathrm{i}}$ とで決まってしまう。従って, 我々が物を 記憶した時には，その情報は，これらの值を変 えて蓄えると考えられ，これらの值を決めるこ とは, 学習そのものと考えられている。そして これらの值は, 急に変らないことから長期的記 憶と呼ばれ, 各ニューロンの時々刻々に変る状 態は短期的記憶と呼ばれる場合もある。

3. フィードフォワード型ネット

ネットワークの型として, 大きく分けて, フィードフォワード型とフィードバック型の二 つがある。まず，前者の代表的な二例を考えて みよう。

3.1 層状ニューラルネットワーク

図 3 に三層ニューラルネットワークを示す。 これは，パターン認識に良く使用されるもので， パターン入力を行う入力層とそれを認識するた めの出力層, その中間に記憶空間を拡大するた めの中間層の三層から成っている。この中間層 は, 外からは隠れているため, Hidden Layer と呼ばれる場合が多い。この場合の学習方法と して良く知られているのがバックプロパゲー

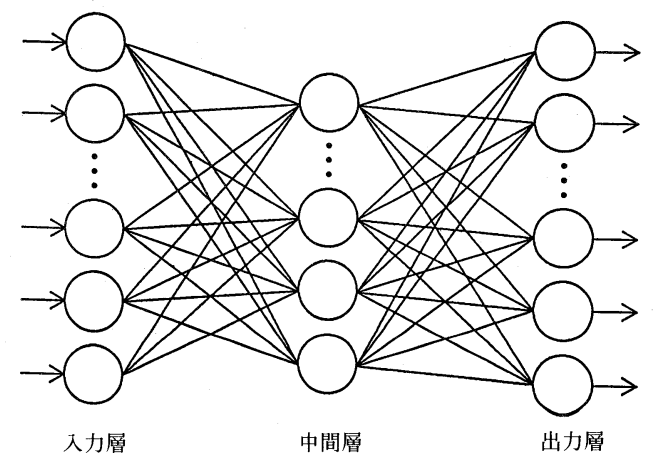

図３三層ニューラルネットワーク

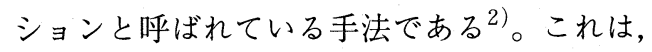
入出力の学習パターン対を多数用意し, それを 再現する（記憶する）ように重みの值を調整す る学習過程において, 誤差関数を導入して, そ れの最小化で行う手法である。例えば， $\mathrm{n}$ 番目 のパターンの出力值を $\mathrm{O}_{\mathrm{k}}(\mathrm{n})$ にしたいとする。 ここで, $\mathrm{k}$ は, 出力層のニューロンの番号を表 わす。この時コスト関数と呼ばれる量 $\mathrm{E}$ を以下 で定義する。

$$
\mathrm{E}=\sum_{\mathrm{k}, \mathrm{n}}\left\{\mathrm{O}_{\mathrm{k}}(\mathrm{n})-\mathrm{U}_{\mathrm{k}}(\mathrm{n})\right\}^{2}
$$

ここで $\mathrm{U}_{\mathrm{k}}(\mathrm{n})$ は, 現在の出力值である。現在の 出力值を目標值に近づけるためには,

$$
\mathrm{E}=0
$$

となるように重みを変えることが出来れば良い。 このため, 重みの修正法として最急降下法を適 用する。即ち, 修正量 $\delta \mathrm{W}_{\mathrm{ij}}$ を, 微小量 $\delta$ に対 して

$$
\delta \mathrm{W}_{\mathrm{ij}}=-\frac{\partial \mathrm{E}}{\partial_{\mathrm{wij}}} \delta
$$

とする。この右辺を実際に計算すると, 出力層 と中間層との間の修正量については簡単に求め られ, 中間層と入力層の間の重み修正量は, 前 者の修正量を用いて表現出来る。この意味でエ ラー修正が入力信号とは逆の方向に行われるた め, エラーバックプロパゲーション法と呼ばれ ている。

この手法は現在一番良く使われるものである が, 良く知られているように, 修正法(4)では $\mathrm{E}$ の極值が求まり，(3)式の解が常に得られるとは 限らない。通常, $\mathrm{E}$ の極值は多数有り, (3)式の 解は（もし有れば）その最小のものである。 従ってこの方法には, 問題が二つある。

1 ) 重みの初期値を変えて最小の極值を求め る必要がある。

2 ）最小の極值が零でない場合には, 中間層 ニューロン数を増す必要がある。

実際には, 解が得られない場合には, その原因 が1) であるのか 2) であるのかの決定はむづ かしい。従って, 試行錯誤的に求めざるを得な い。理論的には, 学習事例 $N$ 個をすべて記憶さ 
せるには，N-1 個の中間層ニューロンがあれ ば充分である ${ }^{3)}$ 。従って, ニューロン数を増や して行けば，必ず学習させることが可能である。 しかしながら，ニューラルネットワークを何ら かの認識装置として使う場合には, 未学習デー 夕に対する認識率が重要である。一般には, 完 全に学習させることは, 最高の認識率を実現す るためには，あまり良く無いと言われている

\section{2 コホーネンネットワーク}

ヘルシンキ工科大学のコホーネンにより提案 されているもので, 一般には, LVQ (Learning Vector Quantization) 法と呼ばれている5)。こ れは, 層状ネットとは全く異なり，ニューロン 一層から成るシステムを考える。各ニューロン には外からパターン信号 $\mathrm{X}=\left(\mathrm{x}_{1}, \mathrm{x}_{2}, \cdots\right)$ が 入って来る (図 4 )。二ューロン $\mathrm{i}$ に入る結合 の重みをべクトルで表現して $\mathrm{W}_{\mathrm{i}}=\left(\mathrm{W}_{\mathrm{i} 1}, \mathrm{~W}_{\mathrm{i} 2}\right.$, …)としてXと $\mathrm{W}_{\mathrm{i}}$ との距離を計算する。別に, ニューロンの近傍 $\mathrm{V}$ を決めておいて, 以下の様

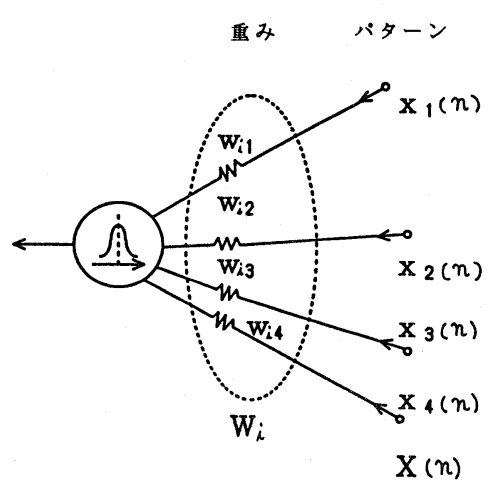

図4 コホーネンネットワーク素子への入カ
な学習則を考える。 $\mathrm{n}$ 番目のパターンX $(\mathrm{n})$ に つき,

1) $\left|\mathrm{W}_{\mathrm{i}}-\mathrm{X}(\mathrm{n})\right|$ が最小となる $\mathrm{i}$ を求める。

2) i の近傍 $\mathrm{V}$ に入るニューロン $\mathrm{j}$ について

$$
\begin{gathered}
\delta \mathrm{W}_{\mathrm{jk}}=\left(\mathrm{x}_{\mathrm{k}}(\mathrm{n})-\mathrm{W}_{\mathrm{jk}}\right) \delta \\
\quad(=0, \text { その他のニューロン }) \\
\text { ここで } \mathrm{x}_{\mathrm{k}}(\mathrm{n}), \mathrm{W}_{\mathrm{jk}} \text { は, } \mathrm{X}(\mathrm{n}), \mathrm{W}_{\mathrm{j}} \text { の } \\
\mathrm{k} \text { 番目の成分。 }
\end{gathered}
$$

3 ) $\mathrm{n}=\mathrm{n}+1$ として 1$)$ にもどる。

これを繰り返すことにより，ニューロン層には， 各パターンnに反応する領域（大きさがほぼ V）が形成されることになる。ニューロン i か らの出力は, $\mathrm{X}$ と $\mathrm{W}_{\mathrm{i}}$ との距離が零で最大にな る(通常の関数 $\mathrm{f}$ とは異なっている)。従って, ニューロン層の発火状態を調べると, 今どんな パターンが入っているか推定できるようになる。 図 5 に入力パターンによって発火領域が変化す る様子の例を示す。

このネットワークの利用は, 各分野で行われ ている。しかし，使い易いネットワークにする ためには，ニューロン層状の発火パターンを認 識するニューロンが必要となり, 結局, 三層 ネットワークの形にする必要があると思われる。 この学習則を使ったネットワークの特徴は, バックプロパゲーションを使ったものに比べ学 習が容易（約10分の 1 ）であり，パターンの追 加, 削除がやり易い6)。また，ニューラルネッ トの構造化と言う観点からは，構造化を自動的 に行う一つの方法として注目されている。

4. フィードフォワード型ネットワーク

ネットワークは, 一般的には, 信号のフィー

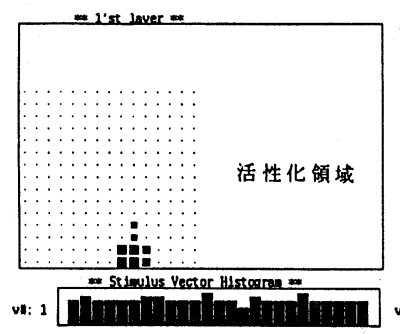

入カパターン

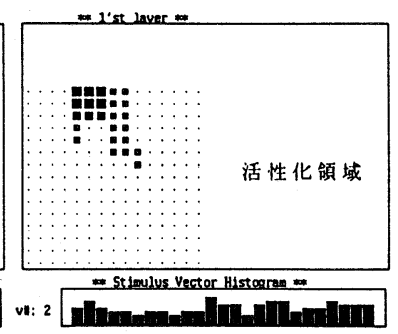

入カパターン

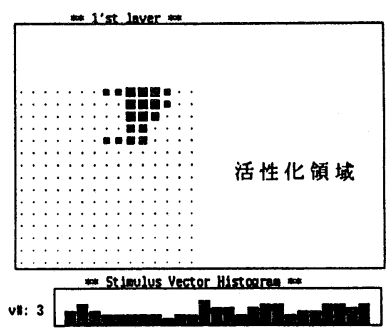

入カパターン

図 5 入カパターンによる活性化領域变化 
ドバックを考える必要がある。この時には，振 舞が複雑になるため解析が困難になる場合が多 い。以下で特徵的なネットワークについて述べ る。

\section{1 メモリー容量}

ニューラルネットワークの動的な振舞は, 定 常状態に近づく場合，周期的な状態になる場合， ランダムな動きをする場合などさまざま有り得 るが, 定常状態は, 記憶（メモリー）として利 用できる。当然ニューロン数 Nが増えれば定常 状態数（メモリー数） M 増大することが予想 される。メモリーとして利用する場合どの位の 容量が期待できるかは, 大変興味ある問題で研 究が行われている。M個のメモリーとなるべき 状態を $U_{i}(m), i=1,2, \cdots, N, m=1$, $2, \cdots, M$ とした時，（1）式において, 重み の值を,

$$
\mathrm{W}_{\mathrm{ij}}=\frac{\sum_{\mathrm{m}} \mathrm{U}_{\mathrm{i}}(\mathrm{m}) \mathrm{U}_{\mathrm{j}}(\mathrm{m})}{\mathrm{M}}
$$

しきい值を零， $\mathrm{f}$ としてステップ関数を用いた ネットワークは，連想メモリーと呼ばれている。 $\mathrm{M}, \mathrm{N}$ が大きい場合で, $\mathrm{U}_{\mathrm{i}}(\mathrm{m})$ の取る值がラン ダムと仮定できる場合には,

$$
\frac{\mathrm{M}}{\mathrm{N}}<\frac{1}{2 \log \mathrm{N}-\log \log \mathrm{N}}, \mathrm{N} \rightarrow \infty
$$

が得られている7)。この結果によると，Nを増 やした場合，メモリー容量はNに比例して増え ないことを示している。特殊なネットワークで はあるが，メモリーの限界を評価する意味で興 味深い結果である。

\section{2 最適化問題}

ニューラルネットワークの動的挙動を考える 場合, ニューロン i に入る全信号量 $\mathrm{X}_{\mathrm{i}}$ の動的 方程式を与えて解析すると全体の動きがつかみ 易い。良く使われる式は， $\mathrm{U}_{\mathrm{i}}\left(\mathrm{X}_{\mathrm{i}}\right)$ をニューロン i の出力信号值として,

$$
\mathrm{C}_{\mathrm{i}} \frac{\mathrm{dX_{ \textrm {i } }}}{\mathrm{dt}}=-\frac{\mathrm{X}_{\mathrm{i}}}{\mathrm{R}_{\mathrm{i}}}+\sum_{\mathrm{j}} \mathrm{W}_{\mathrm{ij}} \mathrm{U}_{\mathrm{i}}\left(\mathrm{X}_{\mathrm{i}}\right)+\mathrm{I}_{\mathrm{i}}
$$

で, $\mathrm{C}_{\mathrm{i}}, \mathrm{R}_{\mathrm{i}}, \mathrm{I}_{\mathrm{i}}$ は定数である。このようなダイ ナミックスを持つネットワークの安定性は, ホップフィールドにより1984年, 議論された ${ }^{8)}$ 。 特に, 重みが対称 $\left(\mathrm{W}_{\mathrm{ij}}=\mathrm{W}_{\mathrm{ji}}\right)$ で $\mathrm{C}_{\mathrm{i}} \mathrm{U}_{\mathrm{i}}^{\prime}>0$ で
ある場合には，以下で示す量 E（グローバル リアプノフ関数) が減少し, その極值の状態に 近づくと言う意味での安定性が示される。ここ で $\mathrm{U}_{\mathrm{i}}^{\prime}$ は $\mathrm{U}_{\mathrm{i}}\left(\mathrm{X}_{\mathrm{i}}\right)$ の微分係数である。

$$
\begin{aligned}
\mathrm{E}=- & \frac{1}{2} \sum_{\mathrm{i}, \mathrm{j}} \mathrm{U}_{\mathrm{i}}\left(\mathrm{X}_{\mathrm{i}}\right) \mathrm{W}_{\mathrm{ij}} \mathrm{U}_{\mathrm{j}}\left(\mathrm{X}_{\mathrm{j}}\right)-\sum_{\mathrm{i}} \mathrm{I}_{\mathrm{i}} \mathrm{U}_{\mathrm{i}}\left(\mathrm{X}_{\mathrm{i}}\right)+ \\
& \sum_{\mathrm{i}} \frac{1}{\mathrm{R}_{\mathrm{i}}} \int^{\mathrm{X}_{\mathrm{i}}} \mathrm{z} \mathrm{U}_{\mathrm{i}}^{\prime}(\mathrm{z}) \mathrm{dz}
\end{aligned}
$$

通常 $\mathrm{U}_{\mathrm{i}}\left(\mathrm{X}_{\mathrm{i}}\right)$ の形は, ステップ関数に近いもの を使うので, 最後の項は零に近い值になる。 従って, 初めの二項で定義される関数の極值が, (7)式で与えられるダイナミックスを持つネット ワークの定常状態で求められることになる。こ れをホップフィールド回路と呼び, $\mathrm{E}$ の最少值

(最適化問題) を高速で解く一つの方法が与え られたことになる。図 6 にアナログ回路例を示 す。

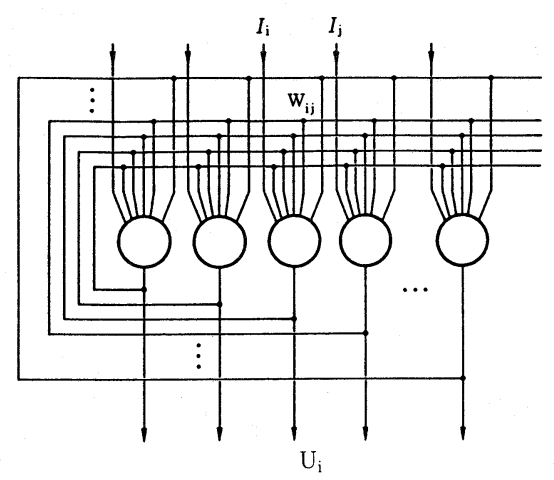

図 6 最適化問題のアナログ回路化例

ホップフィールド回路の適用例はあまり無く, 問題点もある。まずハード的には，アナログで 実現する際に，どう対称性を保障するかであろ う。また, ソフト的には, 最適化問題の定式化 が $\mathrm{E} \geq 0$ で, 解が $\mathrm{E}=0$ で与えられる場合が多 く, ネットワークの定常状態が常には解になら ないことである（極值になっている）。このた め, 試行錯誤的になる場合が多い。しかしなが ら, ニューラルネットワークの別の利用法を示 したと言う意味で大きな影響を与えている。

5. おわりに

以上, ニューラルネットワークの例とその利 
用技術について述べた。これらのものは，現在 研究が続行しており適用分野の拡大や, 利用法 の改良がなされている。バックプロパゲーショ ンやホップフィールド回路を考える場合，大局 的な極小值を求める問題にぶつかり, 結局は, 試行錯誤的な探索を余儀なくされる場合が多い。 そのため, 最初からニューラルネットワークに 確率的な操作を導入する方法も提案されている

$(\text { ボルッマンマシーンと呼ばれる })^{9)}$ 。

ニューラルネットワークと最適化問題とは, その意味付けは明確である。しかしながら，層 状ネットワークが良く適用されるパターン認識 の場合には，学習と認識の関係はあまり明確で は無い。即ち, あるパターン群を学習させ得る かどうかは明確な問題として定式化が可能であ るが，未学習のパターンに関して，それがどれ 位の認識率を有するかは, 明確に定式化出来な い。この問題は, 解決困難な部分を含んでいる。 例えば，入出力関係でシステム同定を行う場合， ニューラルネットワークが良く使われるが，入 出関係だけで充分かと言った問題と同じである。 従って, 当分は, 従来技法との組み合わせや, 適用分野の選択が重要であり, 上手に使い込ん で行く必要があろう。

今回は全く触れなかったが，ニューラルネッ 卜の有用な利用法の一つとして, 生体の神経回 路網を模擬し，生体固有の特徽ある性質を実現 することがある。

例えば，視聴覚機能で良く言われる事は，生 体による知覚の場合, 入力信号の強弱に対応し た感度の変化があり，かなり平均化された信号 として脳に送られている。現在，目の網膜下に ある神経回路を模擬した電子回路の研究が行わ れており，生体と同じ性能を実現している10)。
人間の知識処理機能の解明は, 永遠の課題と して残るかもしれない。しかしながら，人間の 知的機能とは何かと言う問題を考えるより, 現 に実現され，利用出来る機能は何かを考え，応 用して行く事が重要である。その意味において， 多くの分野でニューラルネットワークが適用さ れ，改良され，高度なシステムとして高められ て行くことを切に願うものである。

\section{文献}

1 ) McCulloch, W. S. and Pitts, W., Bulletin of Mathematical Biophysics, 5, 115 (1943)

2 ) Rumelhalt, D. E., Hinton, G. E. and Williams, R. J., Parallel Distributed Processing : Explorations in the Microstructure of Cognition Vol.1, p.318 (1986)

3 ) Arai, M., Proceedings of Intermational Joint Conference on Neural Networks, Vol. 1, 419 (1989)

4 ) Gorman, R. P. and Sejnowski, T. J., Neural Networks, 1, (1), 75 (1988)

5 ) Kohonen, T., Neural Networks, 1, (1), 3 (1988)

6 ) 西村和夫, 川崎美穂, 島田毅, 電学論 $\mathrm{C}$, 110, (3), 126 (1990)

7 ) Amari, S., Neural Network, 1, (1), 63 (1988)

8 ) Hopfield, J. J., Proceedings of the National Academy of Science, USA, 79, 2554 (1982)

9 ) Hinton, G. E. and Sejnowski, T. J., Parallel Distributed Processing : Explorations in the Microstructure of Cognition Vol. 1, p.282 (1986)

10) Mead, C. A. and Mahowald, M. A., Neural Networks, 1, (1), 91 (1988) 